\title{
IS LAPAROSCOPIC SURGERY BECOMING THE FIRST CHOICE IN TREATMENT OF PERFORATED PEPTIC ULCER?
}

\author{
Laura Popa $^{1}$, Florentina Mușat ${ }^{2}$, D.N. Păduraru ${ }^{1,2}$, Alexandra Bolocan ${ }^{1,2}$, O. Andronic ${ }^{1,2}$ \\ ${ }^{1}$ „Carol Davila” University of Medicine and Pharmacy, Bucharest, Romania \\ ${ }^{2}$ General Surgery Department, University Emergency Hospital of Bucharest, Romania
}

\section{REVIEW}

DOI: $10.33695 /$ rojes.v2i1.22

Accepted: 24.05.2020
Corresponding author: Laura Popa

laura.popa.2410@gmail .com

\section{Abstract}

Perforated peptic ulcer (PPU), a significant complication of peptic ulcer disease, has proven to be associated with high rates of mortality and morbidity and to this day, it remains a clear indication of emergency surgery. Whilst open repair remains a feasible treatment option for this complication, the development of laparoscopic surgery has brought along new perspectives, by revealing the benefits and drawbacks of this procedure and therefore raising the question whether it should be the first choice in treatment of a PPU. A literature search was performed using PubMed, Web of Science and Scopus, with the selection of relevant articles from the last 15 years. By comparing the two surgical approaches, conventional and laparoscopic, we aimed to identify the reasons laparoscopy is gaining ground as a mean of treatment of a PPU. Outcomes such as hospital stay, complication rates, use of postoperative analgesics and visual analogue scale favored laparoscopy. The most heterogeneous result was dictated by the operation time, which seems to correlate with multiple factors, a major one being the learning curve and skills this procedure requires. In addition, a significant number of papers had developed patient inclusion and exclusion criteria, which impacted the results of outcomes like morbidity and mortality. There is a lot of evidence that points to laparoscopy becoming the preferred method of treatment of a PPU, however further research is needed in order to reach a consensus.

Keywords: perforated peptic ulcer, laparoscopy, peptic ulcer disease, open repair

\section{Introduction}

Peptic ulcer disease (PUD) is a condition characterized by a defect in the gastric or duodenal mucosa that extends through the muscularis mucosae. It is well known that the etiology of PUD is multifactorial, with Helicobacter Pylori ( $\mathrm{H}$. Pylori) and the overuse of nonsteroidal anti- inflammatory drugs (NSAIDs) constituting the main risk factors [1][2]. That being said, even though the incidence and rates of hospital admission for uncomplicated peptic ulcer have decreased thanks to accurate endoscopic diagnosis and medical treatment, which includes H. Pylori eradication drugs and proton pump inhibitors (PPIs), complicated peptic ulcer is still encountered 
in up to $20 \%$ of these patients [3]. Complications of a peptic ulcer comprise of perforation, bleeding, penetration and gastric outlet obstruction [2]. While most of them can now be successfully managed with alternatives to surgery, like medication or endoscopic intervention, perforated peptic ulcer (PPU) remains the most common indication for emergency surgery [3].

Perforated peptic ulcer (PPU) is a surgical emergency, considered to be of high morbidity and mortality, even up to $30 \%$ unless treated adequately [4]. The main symptoms consist of sudden abdominal pain, tachycardia and abdominal rigidity; however, it is not the only clinical presentation a physician may encounter [4]. Surgical management of a perforated ulcer had been approached conventionally, up until 1990, when the first laparoscopic repair for a perforated duodenal ulcer was reported [5].

Ever since, there have been numerous studies concerned with establishing which of the two approaches is superior. Although most research seems to favor laparoscopy, surgery of PPU is still a subject of debate due to inconsistent results regarding various outcomes like operating time, complications, reoperation, mortality and others [6]. While laparoscopy is making up ground, some surgeons still choose the open repair in surgical management of perforated ulcer.

The aim of this study is to compare the outcomes of a conventional repair to those of a laparoscopic closure and to determine if the advantages that the latter renders, make it the surgical method that should primarily be considered in treating a PPU.

\section{Materials and Method}

A thorough search through PubMed, Web of Science and Scopus, using the following search formula: (laparoscop*) AND (open repair) AND (perforated peptic ulcer) was performed. Only full text articles published in the last 15 years were chosen, with the exception of 2 articles necessary for historical reference. After careful consideration articles that were most relevant to the subject of our review were included. In the end we managed to include a total of 30 articles in our research.

\section{Results and Discussion}

30 relevant articles were found, out of which 9 are general articles that currently summarize what is known about laparoscopy as a mean of treatment of PPU. We comprised the results of the 21 articles left, out of which only 4 incorporated some form of randomization.

Patient selection criteria and exclusion

Most studies included patients based on their symptoms and diagnosis of a perforated peptic ulcer. Only a few of them included patients regardless of their comorbidities or severity of their affliction [7], [8].

Out of all the studies, the majority had some exclusion criteria, with the most prominent being severe comorbidities, gastric malignancies or suspicion of gastric malignancy perforation, concomitant bleeding ulcer, pregnancy, scarring from previous surgeries or sepsis [9]-[14]. Even though the Boey and ASA scores were included in the patient's evaluation in most of the research, only three papers referenced them as exclusion criteria [10], [15], [16].

The Boey and ASA score are two of the most employed scoring systems for outcome predictions in patients with PPU. The Boey score was the first score to measure the 30 day mortality outcome, by evaluating parameters such as perforation over 24 hours, shock and other severe comorbidities. It is considered that patients that present with all the factors have a $100 \%$ mortality rate [17], [18]. The ASA score is a comorbidity score useful in indicating the physical status of a patient and predicting operative risk. It is commonly paired with other descriptive patient data. [17], [19]. One study showed 
strong evidence of how the score impacts morbidity and mortality, by separating the groups based on the class (ASA 1-3 vs. ASA 4-5) in order to illustrate a more accurate analysis [20].

The trends of inclusion and exclusion in the studies we found pose the question whether or not the laparoscopic approach tends to be favored due to the fact that patients at a less risk of developing serious complications benefit from this surgical approach. One study suggests that since laparoscopy has proven to associate with better outcomes such as hospital stay, postoperative pain and less complications, it could on the contrary be beneficial for high risk patients [21].

We will now discuss the most frequent outcomes evaluated in the studies.

\section{Operation time}

The majority of the studies we included measured the operating time as one of the outcomes, however the results seem to indicate an important heterogeneity. Even though some of them favor laparoscopy, the concern is that this approach can require more time due to factors such as inexperienced surgeons, necessity of peritoneal lavage and suturing of frayed margins of the ulcer [8],[22]. Two studies displayed a significantly shorter time for the laparoscopic approach, attesting that this domain requires practice and skills [7], [13].

\section{Complications and conversion rates}

We concluded that there were overall more complications in the open repair groups, however not all the results were statistically significant. The main laparoscopic complication surgeons worry about is suture leak, but there seems to be no significant difference between the open repair group and the laparoscopy one in any of the studies. Conversion rates were generally low, with the exception of a few studies, with the most common reasons for conversion being inability to visualize ulcers, use of laparoscopy with diagnostic intent only, difficulty in exploration adhesions and gastric malignancies [23], [24].

Another two important measured outcomes were mortality and morbidity. The consensus is that laparoscopy is associated with smaller rates than a conventional approach, however few results were statistically significant [10], [25]. One study focused solely on the 30-day mortality and after careful matching, observed that the results were similar between the groups undergoing the procedures [26].

This again raises the question whether these outcomes are correlating with the careful selection of the patients undergoing one type of surgery or the other.

\section{Hospital stay}

This outcome had the most homogenous measurements, with laparoscopy proving to be at a noteworthy advantage over the open repair of PPU. However, two of the randomized studies showed no significant difference in the median hospital stay [8], [11].

\section{Analgesics and VAS scale}

The least assessed outcomes were postoperative pain management and postoperative requirement of analgesics.

Postoperative pain was evaluated using the Visual Analog Scale (VAS), which comprises of an intensity scale measured from 0 to 10 , with the latter being the "worst imaginable pain" [27]. All of the studies evaluating this outcome significantly favored the laparoscopic repair [8], [10], [12], [28]. The LAMA trial also took into consideration the postoperative scar's appearance, which was significantly better in the laparoscopy group [8]. In terms of analgesics, it was concluded that patients treated for PPU using the laparoscopic approach required less postoperative analgesics compared to those who underwent an open repair. An aspect worth mentioning is how history of opium consumption in patients can interfere with the possibility of determining the postoperative analgesic use [29]. 
We also reviewed two studies which did not compare the two surgical approaches used in treatment of a perforated peptic ulcer, however both had results that support laparoscopy as a feasible, safe and reliable option in managing a PPU [29], [30].
Albeit, after analyzing all of the included studies together, we have decided to also list the main points of those that employed some form of randomization below (Table $\quad$ 1, Table 2 ).

\begin{tabular}{cccc}
\hline STUDY & Form of randomization & Number of patients & Procedure \\
\hline Bertleff et al. & computer generated with sealed envelope & 101 & $\begin{array}{c}\text { Lap 52 } \\
\text { OR 49 }\end{array}$ \\
\hline Ge et al. & computer generated & 119 & $\begin{array}{c}\text { Lap 58 } \\
\text { OR 61 }\end{array}$ \\
\hline Shah et al. & unspecified & 50 & $\begin{array}{c}\text { Lap 25 } \\
\text { OR 25 }\end{array}$ \\
\hline Motewar et al. & serial randomization & 140 & $\begin{array}{c}\text { Lap 70 } \\
\text { OR 70 }\end{array}$ \\
\hline
\end{tabular}

Table 1. Studies that included a form of randomization, $L a p=$ laparoscopy, $O R=$ open repair

\begin{tabular}{c|cccc}
\hline STUDY & Operating time & Complications & Hospital stay & $\begin{array}{c}\text { Analgesics/ VAS } \\
\text { scale }\end{array}$ \\
\hline Bertleff et al. & Favors OR & $\begin{array}{c}\text { Favor Lap, not } \\
\text { statistically significant }\end{array}$ & Favors Lap & Favors Lap \\
\hline Ge et al. & $\begin{array}{c}\text { Similar } \\
\text { operating time }\end{array}$ & $\begin{array}{c}\text { Favors Lap, not } \\
\text { statistically significant }\end{array}$ & Favors Lap & Favors Lap \\
\hline Shah et al. & Favors Lap & $\begin{array}{c}\text { Favors Lap, not all } \\
\text { statistically significant }\end{array}$ & Favors Lap & Favors Lap \\
\hline Motewar et al. & $\begin{array}{c}\text { Similar } \\
\text { operating time }\end{array}$ & $\begin{array}{c}\text { Favors lap, not all } \\
\text { statistically significant }\end{array}$ & - & - \\
\hline
\end{tabular}

Table 2 - Main outcomes of the randomized studies

\section{Conclusions}

Laparoscopic management of a perforated peptic ulcer is becoming the first choice in treatment of this affliction, however a few aspects are still unclear and they require further research. While this technique is advancing and proving to be superior to an open repair in regards to certain outcomes detailed above, some drawbacks still cause a degree of uncertainty whether or not laparoscopy should be the treatment option surgeons need to rely on. Our study synthetizes what is currently known about the comparison between the two surgical approaches by focusing on the most measured outcomes. We believe that with more randomized clinical trials and studies that include a larger population, there can be a stronger confirmation that laparoscopy is taking over as a method of treatment of a PPU.

\section{References}

[1] D. Vaira, J. Holton, M. Miglioli, M. Menegatti, P. Mule, and L. Barbara, "Peptic ulcer disease and Helicobacter pylori infection," Current Opinion in Gastroenterology, vol. 10, no. 1. Lippincott Williams and Wilkins, pp. 98-104, 1994.

[2] K. Ramakrishnan and R. C. Salinas, "Peptic ulcer disease," American Family Physician, vol. 76, no. 7. 01-Oct-2007.

[3] A. Tarasconi et al., "Perforated and bleeding peptic ulcer: WSES guidelines," 
World Journal of Emergency Surgery, vol. 15, no. 1. BioMed Central Ltd., pp. 1-24, 07Jan-2020.

[4] K. T. Chung and V. G. Shelat, "Perforated peptic ulcer - an update," World J. Gastrointest. Surg., vol. 9, no. 1, p. 1, 2017. [5] P. Mouret, Y. François, J. Vignal, X. Bartht, and R. Lombard-Platet, "Laparoscopic treatment of perforated peptic ulcer," Br. J. Surg., vol. 77, no. 9, pp. 1006-1006, 1990.

[6] S. Tan et al., "Laparoscopic versus open repair for perforated peptic ulcer: A meta analysis of randomized controlled trials," International Journal of Surgery, vol. 33. Elsevier Ltd, pp. 124-132, 01-Sep-2016.

[7] R. Laforgia et al., "Laparoscopic and Open Surgical Treatment in Gastroduodenal Perforations: Our Experience," Surg. Laparosc. Endosc. Percutaneous Tech., vol. 27, no. 2, pp. 113-115, 2017.

[8] M. J. O. E. Bertleff et al., "Randomized clinical trial of laparoscopic versus open repair of the perforated peptic ulcer: The LAMA trial," World J. Surg., vol. 33, no. 7, pp. 1368-1373, Jul. 2009.

[9] B. Ge et al., "Stomach A prospective randomized controlled trial of laparoscopic repair versus open repair for perforated peptic ulcers."

[10] H. A. Wadaani, "Emergent laparoscopy in treatment of perforated peptic ulcer: A local experience from a tertiary centre in Saudi Arabia," World J. Emerg. Surg., vol. 8, no. 1, Mar. 2013.

[11] A. Motewar, M. Tilak, D. S. Patil, N. Bhamare, and L. Bhople, "Laparoscopic versus open management of duodenal perforation: A comparative study at a District General Hospital," Prz. Gastroenterol., vol. 8, no. 5, pp. 315-319, 2013.

[12] S. L. Siow, H. A. Mahendran, C. M. Wong, M. Hardin, and T. L. Luk, "Laparoscopic versus open repair of perforated peptic ulcer: Improving outcomes utilizing a standardized technique," Asian J. Surg., vol. 41, no. 2, pp. 136-142, Mar. 2018.
[13] V. Golash, "Ten-Year Retrospective Comparative Analysis of Laparoscopic Repair versus Open Closure of Perforated.," Oman Med. J., vol. 23, no. 4, pp. 241-6, Oct. 2008. [14] F. H. Shah, S. G. Mehta, M. D. Gandhi, and Saraj, "Laparoscopic Peptic Ulcer Perforation Closure: the Preferred Choice," Indian J. Surg., vol. 77, no. Suppl 2, pp. 403406, Dec. 2015.

[15] S. A. Stepanyan et al., "Laparoscopic and open repair for perforated duodenal ulcer: Single-center experience," Wideochirurgia I Inne Tech. Maloinwazyjne, vol. 14, no. 1, pp. 60-69, 2019.

[16] A. Mirabella et al., "Laparoscopy is an available alternative to open surgery in the treatment of perforated peptic ulcers: a retrospective multicenter study," BMC Surg., vol. 18, no. 1, Sep. 2018.

[17] K. Thorsen, J. A. Søreide, and K. Søreide, "Scoring systems for outcome prediction in patients with perforated peptic ulcer," Scandinavian Journal of Trauma, Resuscitation and Emergency Medicine, vol. 21, no. 1. BioMed Central, p. 25, 10-Apr2013.

[18] S. Di Saverio et al., "Diagnosis and treatment of perforated or bleeding peptic ulcers: 2013 WSES position paper," World Journal of Emergency Surgery, vol. 9, no. 1. BioMed Central Ltd., p. 45, 03-Aug-2014.

[19] D. J. Doyle and E. H. Garmon, American Society of Anesthesiologists Classification (ASA Class). StatPearls Publishing, 2018.

[20] M. Žáček, J. Váňa, and B. Babiš, "Laparoscopic closure of perforated gastroduodenal ulcer: 15 years' experience in our centre," Videosurgery Other Miniinvasive Tech., vol. 4, pp. 578-585, 2014.

[21] M. H. Jamal et al., "Laparoscopy in Acute Care Surgery: Repair of Perforated Duodenal Ulcer," Med. Princ. Pract., vol. 28, no. 5, pp. 442-448, Sep. 2019.

[22] D. J. K. Lee, M. Ye, K. H. Sun, V. G. Shelat, and A. Koura, "Laparoscopic versus Open Omental Patch Repair for Early 
Presentation of Perforated Peptic Ulcer: Matched Retrospective Cohort Study.," Surg. Res. Pract., vol. 2016, p. 8605039, 2016.

[23] A. C. Critchley, A. W. Phillips, S. M. Bawa, and P. V. Gallagher, "Management of perforated peptic ulcer in a district general hospital,” Ann. R. Coll. Surg. Engl., vol. 93, no. 8, pp. 615-619, Nov. 2011.

[24] M. F. Çelik et al., "Erken başvurulu peptik ülser perforasyonu olgularinda laparoskopik onarimin artan yeri," Turkish J. Surg., vol. 30, no. 3, pp. 120-124, 2014.

[25] P. Budzyński et al., "Changing patterns in the surgical treatment of perforated duodenal ulcer - Single centre experience," Wideochirurgia I Inne Tech. Maloinwazyjne, vol. 10, no. 3, pp. 430-436, Sep. 2015.

[26] S. Zogovic, A. B. Bojesen, S. Andos, and F. V. Mortensen, "Laparoscopic repair of perforated peptic ulcer is not prognostic factor for 30-day mortality (a nationwide prospective cohort study)," 2019.

[27] G. A. Hawker, S. Mian, T. Kendzerska, and M. French, "Measures of adult pain: Visual Analog Scale for Pain (VAS Pain),
Numeric Rating Scale for Pain (NRS Pain), McGill Pain Questionnaire (MPQ), ShortForm McGill Pain Questionnaire (SF-MPQ), Chronic Pain Grade Scale (CPGS), Short Form-36 Bodily Pain Scale (SF-36 BPS), and Measure of Intermittent and Constant Osteoarthritis Pain (ICOAP)," Arthritis Care Res., vol. 63, no. SUPPL. 11, pp. S240-S252, Nov. 2011.

[28] N. Cui, J. Liu, and H. Tan, "Comparison of laparoscopic surgery versus traditional laparotomy for the treatment of emergency patients," J. Int. Med. Res., p. 030006051988919 , Dec. 2019.

[29] M. Alemrajabi, S. Safari, A. Tizmaghz, F. Alemrajabi, and G. Shabestanipour, "Laparoscopic Repair of Perforated Peptic Ulcer: Outcome and Associated Morbidity and Mortality," Electron. physician, vol. 8, no. 6, pp. 2543-2543, Jun. 2016.

[30] H. Aljohary, H. Althani, G. Elmabrok, K. Hajaji, and I. Taha, "Outcome of laparoscopic repair of perforated duodenal ulcers," Singapore Med. J., vol. 54, no. 4, pp. 216-219,

2013. 